\title{
DÜBLIN
}

Technological University Dublin

ARROW@TU Dublin

\section{The Link between Spatial Skills and Engineering Problem-Solving}

\author{
Gavin Duffy \\ Technological University Dublin, gavin.duffy@tudublin.ie \\ Sheryl Sorby \\ University of Cincinnati \\ Presentacion Rivera Reyes \\ State University of New York at Buffalo
}

See next page for additional authors

Follow this and additional works at: https://arrow.tudublin.ie/engineduccon

Part of the Engineering Education Commons, and the Other Engineering Commons

\section{Recommended Citation}

G. Duffy, S. Sorby, P. R. Reves, T. Delahunty, L. Perez and J. Ravishankar, "The Link between Spatial Skills and Engineering Problem-Solving," 2018 IEEE International Conference on Teaching, Assessment, and Learning for Engineering (TALE), 2018, pp. 272-278, doi: 10.1109/TALE.2018.8615193.

This Conference Paper is brought to you for free and open access by the Engineering: Education and Innovation at ARROW@TU Dublin. It has been accepted for inclusion in Conference papers by an authorized administrator of ARROW@TU Dublin. For more information, please contact arrow.admin@tudublin.ie, aisling.coyne@tudublin.ie,gerard.connolly@tudublin.ie. Funder: National Science Foundation (USA)

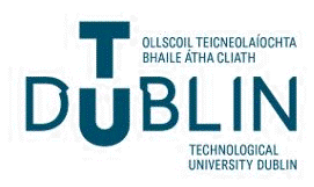




\section{Authors}

Gavin Duffy, Sheryl Sorby, Presentacion Rivera Reyes, Tom Delahunty, Lance Perez, and Jayashri Ravishankar 


\section{The Link between Spatial Skills and Engineering Problem-Solving}

\author{
Gavin Duffy \\ School of Electrical and Electronic \\ Engineering \\ Dublin Institute of Technology \\ Dublin, Ireland \\ gavin.duffy@dit.ie \\ Tom Delahunty \\ College of Engineering \\ University of Nebraska-Lincoln \\ Lincoln, NE, USA \\ tdelahunty2@unl.edu
}

\author{
Sheryl Sorby \\ Department of Engineering Education \\ University of Cincinnati \\ Cincinnati, $\mathrm{OH}$, USA \\ sheryl.sorby@uc.edu \\ Lance Perez \\ College of Engineering \\ University of Nebraska-Lincoln \\ Lincoln, NE, USA \\ lcperez@unl.edu
}

\author{
Presentacion Rivera Reyes \\ Department of Engineering Education \\ University at Buffalo \\ Buffalo, NY, USA \\ privera1@buffalo.edu \\ Jayashri Ravishankar \\ School of Electrical Engineering and \\ Telecommunications \\ University of New South Wales \\ Sydney, Australia \\ jayashri.ravishankar@unsw.edu.au
}

\begin{abstract}
Well-developed 3-D spatial skills are correlated with engineering success. However, most studies examining the link between spatial skills and engineering success have been conducted at the macro level, i.e., the link between spatial skills and course grades or between spatial skills and graduation rates. In this research, a more refined approach has been taken. Relationships between spatial skills and success in solving certain types of problems that engineering students commonly encounter are examined. It was found that high levels of spatial skills predict success in solving certain types of engineering problems but not in all types of problems. Data gathered through this research will be further analyzed to determine characteristics of problems where spatial skills appear to play a role and characteristics where they do not.
\end{abstract}

Keywords—spatial skills, problem-solving, engineering student success

\section{BACKGROUND}

Engineers are known problem-solvers. Through their rigorous education and subsequent practice, they learn to solve complex open-ended problems for the betterment of society. What is less well-known is that professional engineers are also great visualizers. In tests with more than 30,000 professionals [1], engineers demonstrated the highest level of spatial visualization skills, followed closely by architects and other STEM professionals. A recent study shows a strong correlation between spatial visualization skills and creativity and technical innovation [2]. This leads to the hypothesis that undergraduate engineering degree programs should produce graduates with well-developed spatial skills if we are to produce engineers who are capable of solving the challenging and multidisciplinary problems our society faces.

Engineering is one of the largest career disciplines in the U.S. It is estimated that approximately 6.2 million people work in science and engineering related disciplines in the United States [3] and this is projected to grow substantially in the next decade [3]. Therefore, it is apparent that engineering education has a critical role within higher education. There have been a number of reports and studies citing deficiencies in the current provision of engineering education in general and calling for widespread change [4]. In particular, reports such as NAE [5] have highlighted sub-standard problem solving skills in the workforce as a major concern among new graduates of engineering disciplines.

While problem type can vary from open-ended, ill-defined with divergent solutions to well-defined, convergent problems, the way we think about problem formulation and how we translate a problem statement into a representation is often studied using simple math problems. For example, Clement [6] gave the following problem to 150 freshman engineering students:

"Write an equation using the variables $\mathrm{C}$ and $\mathrm{S}$ to represent the following statement:

At Mindy's restaurant, for every four people who ordered cheesecake, there are five people who ordered strudel.

Let $\mathrm{C}$ represent the number of cheesecakes and $\mathrm{S}$ the number of strudels." [6]

He found the success rate to be very low - $27 \%$ approximately two out of three engineering students with high levels of math ability were unable to convert the word statement into the correct equation $(5 \mathrm{C}=4 \mathrm{~S})$. It appeared that many translated the statement one word one at a time to arrive at the following incorrect response: $4 \mathrm{C}=5 \mathrm{~S}$ which was provided by $68 \%$ of the sample. Other studies in the literature support this fact that it is not easy to translate simple word problem statements to mathematical form. The process of forming a correct representation is not easy. Even rephrasing a problem without changing the mathematical properties will success rate [7] and the approach to solving the problem [8]. It is apparent that, for many, simple problems can be very difficult to solve; comprehending and translating the problem statement can be very difficult even when the mathematical procedures are simple 
Therefore, it is important to consider manners in which the development of problem solving abilities can be fostered within these new conceptions of engineering education. One area which is significant in fostering improvements among engineering education students is spatial ability [9].

Although spatial thinking has been a part of the national mathematics standards in the U. S. for many years [10] it is not always specifically assessed on the high stakes tests in most states and therefore is not a part of the mathematics curriculum. Despite the clear importance of spatial skills for STEM careers these skills are unlikely to be consistently taught in schools. Providing educators with an evidence-based approach to training spatial skills could greatly enhance "uptake" of the need to teach these skills and the benefit of doing so.

Spatial skills have been a significant area of research in educational psychology since the 1920 s or 30s. In his "A Plea for Visual Thinking" Arnheim [11] asserts that most educational psychologists erroneously believe that there is a distinct dichotomy between perception (visual thinking) and reasoning (cognitive thinking). He states that as far back as Descartes, the reasoning abilities of humans were considered to be superior to their perceiving abilities. Arnheim argues that perception and reasoning are both necessary in the thinking process and that to elevate the reasoning thinking skills above the visual thinking skills is to ignore the wat that the mind actually works. In fact, he believes, that "Thinking, then, is mostly visual thinking."

There is now very strong correlational evidence linking spatial skills to success in STEM [12], [13], [14]. Recent articles link spatial skills to creativity and technical innovation [2] and to success in computer programming [15]. A recent longitudinal study following 400,000 high school students $11+$ years later, investigated both their choice of college major and career, and found that adolescent spatial reasoning skills were predictive of choice of STEM majors and careers, above and beyond the effects of verbal and math abilities [14]. The researchers analyzed longitudinal data for predictors of achievement and attainment in STEM fields using nationally representative samples that included a total of over 100,000 participants. Spatial ability emerged as a consistent and statistically independent predictor of selecting STEM related courses, graduate study, and other measures of STEM attainment.

The good news is that spatial skills can be learned. In an extensive meta-analytic study, Uttal et al. [16] demonstrated that generally spatial skills training results in an improvement (equating to an effect size of 0.47 ) in spatial ability. This demonstrates that spatial skills can be effectively learned and have the potential to facilitate significant gains in learning within engineering [16].

Spatial skills training may play a particularly important role in promoting gender equity in STEM achievement and attainment. It is well-documented that the 3-D spatial visualization skills of women lag behind those of their male counterparts, especially for 3-D rotations [17], [18], [19]. Theories for the cause of these differences include the assertion that gender differences in spatial ability reflects our evolutionary past and may be influenced by levels of androgens e.g., [20] [21]. Other theorists suggest that environmental factors are the primary reasons for male-female differences in spatial skill levels [22]. A meta-analysis of sex differences in spatial ability estimated an effect size difference of +.56 on mental rotation tasks [19], with a female disadvantage. Given the evidence for the importance of three-dimensional spatial thinking in many domains of science, the female disadvantage on mental rotation tasks may make a direct contribution to females' lower rate of representation at higher levels of math and science.

Sorby has developed the Developing Spatial Thinking (DST) curriculum that consists of a workbook and software that helps students to develop their 3-D spatial skills. The onecredit intervention course at the university level that uses this curriculum is aimed at first-year engineering students with weak spatial skills. The spatial skills intervention course has been adopted at a number of colleges of engineering across the U. S. Longitudinal studies have shown the efficacy of the curriculum with the following key outcomes [23] [24]:

- The spatial skills of the students who participated in the course increased significantly.

- Increases were uniform for both the males and the females.

- The students who participated in the course went on to earn higher grades in their introductory engineering, calculus, chemistry, computer science, and physics courses.

- More students graduated from engineering. This was particularly true for women students. [In one study the engineering graduation rate for women in the intervention was $77 \%$ compared to $47 \%$ for women not in the intervention.]

Several tests have been developed to measure a person's spatial skill level. The two predominant tests used in engineering education research are the Purdue Spatial Visualization Test: Rotations (PSVT:R) [25] and the Mental Cutting Test (MCT) [26]. Example problems from each of these tests are given in Figures 1 and 2.

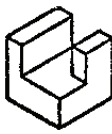

IS ROTATED TO
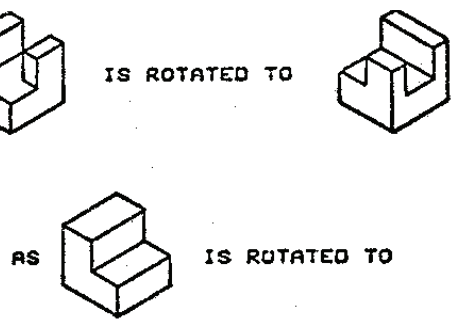

IS RUTATED TO

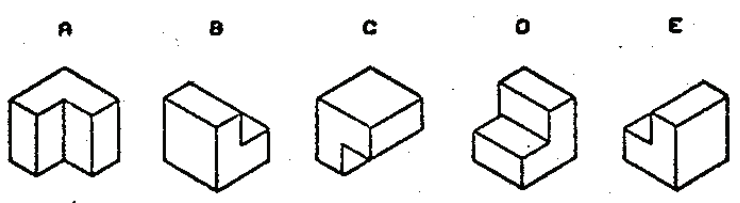

Fig. 1. Sample Problem from the PSVT:R (correct answer D) 


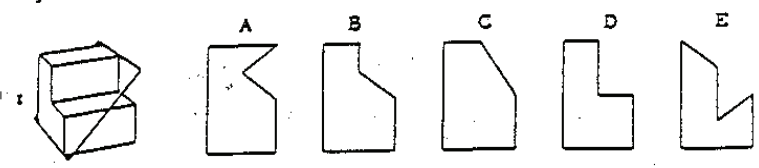

Fig. 2. Sample Problem from the MCT (correct answer D)

\section{Research Design}

In this research, tests of spatial cognition were administered to engineering students at a variety of institutions in the U. S. and in Australia. Table 1 includes data regarding the various test administrations in this study. The insitutions involved in this study were Insitution 1, Institution 2, Institution 3, Institution 4, and Institution 5. In addition to the spatial skills tests, students solved several problems in either mathematics, electrical engineering or chemical engineering, depending on major and level of experience.

TABLE I. SPATIAL TEST ADMINISTRATION

\begin{tabular}{|l|l|c|c|}
\hline Institution & $\begin{array}{c}\text { Test } \\
\text { Administered }\end{array}$ & $\begin{array}{c}\text { Sample } \\
\text { Size }\end{array}$ & Student Major/level \\
\hline 1 & PSVT:R & 276 & Various $/ 1^{\text {st }}$ year \\
\hline 1 & MCT & 114 & Various $/ 1^{\text {st }}$ year \\
\hline 1 & MCT & 27 & Electrical Eng $/ 3^{\text {rd }}$ year \\
\hline 2 & MCT & 97 & Electrical Eng \\
\hline 3 & PSVT:R & 115 & Various $/ 1^{\text {st }}$ year \\
\hline 4 & MCT & 64 & Chemical Eng $/ 3^{\text {rd } y e a r ~}$ \\
\hline 5 & MCT & 17 & Electrical Eng $/ 3^{\text {rd }}$ year \\
\hline
\end{tabular}

\section{A. Mathematics Problems}

Two types of math problems were administered to first year engineering students at Institution 1 and 3. Approximately half of the problems were word problems and the other half were questions designed to evaluate procedural math knowledge. For example, one word problem was:

- You have a square lawn. You increase one side of the lawn by 2 meters and the other side by 3 meters. The area of the lawn is now twice the area of the original lawn. What was the original size of the lawn?

The corresponding question used to assess basic procedural knowledge related to this problem was:

- Find the roots of $2 x^{2}+6 x-8=0$ using factoring

\section{B. Electrical Engineering-DIRECT Test}

Electric circuits is a core subject in electrical engineering and the physical sciences that is typically introduced in the first few semesters of study. Learning outcomes in this subject relate to the comprehension of several concepts associated with direct current (DC) circuits including energy, voltage/potential difference and current. Also included in these learning outcomes is the ability to create and interpret formal circuit diagrams which requires knowledge of laws, rules and symbols guided by conceptual understanding. Since electric circuit diagrams are well-structured images and definitions of spatial ability typically refer to the ability to visualize well-structured images [27], it seems plausible there should be a relationship between spatial ability and performance in electric circuit diagram tasks.

A conceptual test of electric circuits called DIRECT [28] was administered to a portion of the electrical engineering students participating in this study. The DIRECT test consists of 29 multiple choice questions that cover four areas of understanding: concepts of energy, voltage, current and physical aspects of circuits such as open and closed circuit properties. Samples for this portion of the study were recruited from Institutions 1 and 2.

\section{Electrical Engineering-General Circuits Problems}

A second group of electrical engineering students completed a set of circuits problems using pencil and paper from Institution 5. This task consisted of 7 multiple-choice knowledge control questions, 11 multiple-choice electric circuit questions, and 5 problem-solving electric circuit questions.

The knowledge control questions were developed to determine the level of conceptual understanding by the students of the topics required to successfully respond to the remaining 16 electric circuit problems. The knowledge control questions covered Ohm's Law, series and parallel resistance, power, Kirchhoff's Voltage Law and Kirchhoff's Current Law, and Thevenin equivalent circuits. Given the importance of conceptual understanding when problem-solving [29], it was necessary to control for the students understanding of these concepts. The 11 multiple-choice electric circuit questions were selected from the Direct 1.1, a concept inventory developed to evaluate resistive electrical circuit concepts [28]. The final 5 electric circuit problems were selected from textbooks that are commonly used in undergraduate circuit courses in the United States. The students were given one hour to complete all 23 circuits problems.

\section{Chemical Engineering Problems}

Students enrolled in a 3rd year course in a Chemical Engineering program at Insitution 4 solved problems based on concepts learned in a prerequisite course. Some of the problems utilized typical chemical engineering concepts re-framed with "everyday" examples and other problems were taken directly from chemical engineering textbooks. Examples of these two types of problems are given in the following:

- One vegetable oil contains $8 \%$ saturated fats and a second oil contains $26 \%$ saturated fats. In making a salad dressing from these two oils how many ounces of the second must be added to 10 ounces of the first in order for the dressing to have $14 \%$ saturated fats.

- One thousand kilograms per hour of a mixture of benzene and toluene containing $50 \%$ benzene by mass is separated by distillation into two fractions. The mass flow rate of benzene in the top stream is $450 \mathrm{~kg} /$ hour and that of toluene in the bottom stream is $475 \mathrm{~kg} / \mathrm{h}$. The operation is at steady state. Calculate the component flow rates in the output streams 


\section{RESULTS}

The results obtained from this study are described in the next paragraphs, delineated according to discipline/level.

\section{A. Mathematics}

In the analysis of the word problems administered, it was found that scores on the spatial test were significantly related to success in solving the problems; however, the relationship between spatial ability and the set of 6 procedural questions was small and insignificant. Hegarty \& Kozhevnikov [30] measured a large and significant correlation $(\mathrm{r}(31)=.52, \mathrm{p}<$ $.01)$ between a set of math story problems and a test of spatial ability among $6^{\text {th }}$ grade boys (12 years old). Therefore, the relationship between spatial ability and word problem solving that was shown to be evident among samples of $6^{\text {th }}$ grade children was also shown to be present among samples of engineering students. It is quite plausible this relationship persists throughout adolescence and can be found in a variety of samples.

In order to learn why high spatial students outperform their low spatial counterparts in solving word problems, the solutions provided by each participant to the 6 problems were coded based on a set of actions that together constituted an approach to problem solving. It was found that high spatial students were consistently more successful at both linguistic and schematic levels as evidenced by translating relational and assignment statements to mathematical form (linguistic knowledge) and by selecting an appropriate schema on which to base the solution (schematic knowledge). In other words, if problem representation consists of the phase that culminates in the creation of a mathematical model which is then subjected to standard mathematical procedures in a solution phase, spatial ability is relevant to problem representation only and unrelated to problem solution. High spatial students make fewer errors compared to low spatial students when translating word statements that assign values to and/or relations between variables/constants and are also more likely to select a correct schema for the problem. They are therefore placed in a better position before the solution phase begins. However, if both low and high spatial students arrive at the solution phase with the correct representation their subsequent performance and chances of getting the correct answer are equal.

To illustrate the different approaches to solving a problem, examples collected from participants are presented below taken from the solutions to the 'Lawn Problem':

"A square lawn was extended in width by $2 \mathrm{~m}$ and in length by $3 \mathrm{~m}$. The area of the new lawn is twice as big as the area of the old lawn. What are the measurements of the old lawn?"

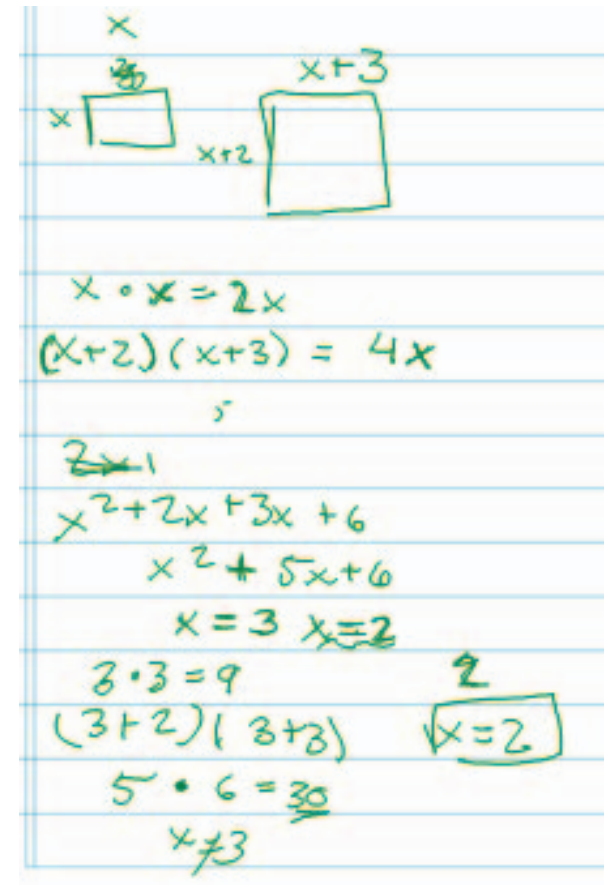

Fig. 3. Lawn problem solution from P43 (PSVT:R = 15).

In the solution shown in Figure 3, P43 correctly treats the lawn as a square, translates the change in width and length and uses the area schema but makes an error in equating old and new areas. The new area is given as $4 \mathrm{x}$ where it should be $2 \times 2$. This could be a typographical error in placing the 2 as a multiplier rather than exponent of $\mathrm{x}$ but the second half of the solution omits the new area altogether. In fact, there is no equation in the second part, just the quadratic expression which is factorized incorrectly to give $\mathrm{x}=2$ or 3 with $\mathrm{x}=2$ selected as the correct answer. P43 does treat the lawn as square, correctly identifies the new dimensions and area schema and could be seen as correctly identifying the change in area but fails to enact this latter aspect in an appropriate way.

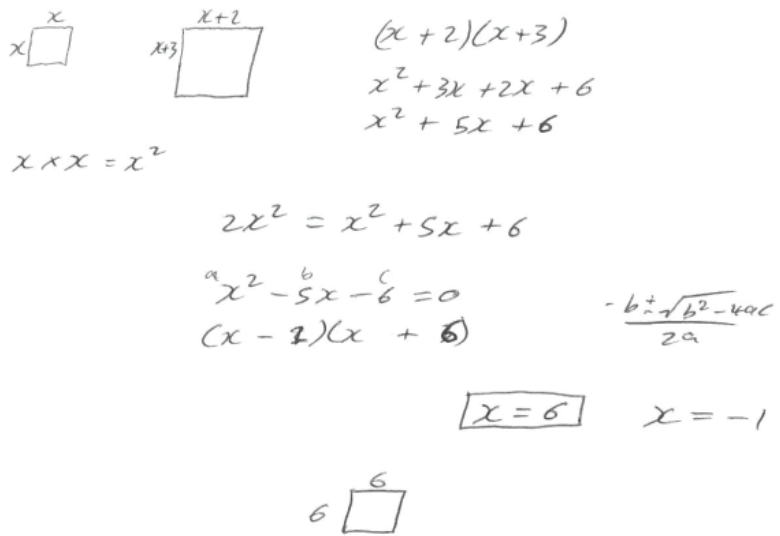

Fig. 4. Lawn problem solution from P113 (PSVT:R = 30). 
In contrast, there is no confusion evident in the solution provided by P113 that the lawn is square (see Figure 4). It is clearly treated as a square at the start and when the solution is checked at the end. The problem statement contains four ingredients that are required to write the equation; three are linguistic, they are contained in the words of the problem - the lawn is square, width $+2 \&$ length +3 , and Anew $=2 \times$ Aold and one is a schema selected by the participant - area $=$ width $\mathrm{x}$ length. Taken as a scale of four ingredients, high spatial students scored significantly higher on this scale than low spatial students. It was consistency in forming the full representation rather than any one aspect of the representation that was the differentiating feature.

Or, to put it another way that may resonate with models of working memory, high spatial students were better at avoiding errors in representation while low spatial students were more likely to omit or err in one or more of the ingredients. Given that working memory is notoriously limited in capacity [31], that these problems are novel to the students and solutions are not readily available in long term memory, it is likely that solving these problems places high demands on working memory. A key component of working memory is the visuospatial sketchpad [32]. Assuming the PSVT:R provides a measure of visuospatial working memory [33], participants in this study were more successful at problem representation because they had higher working memory capacity which led to fewer errors being made in problem representation.

A key finding from this work is that problem solving in this context consists of two cognitively distinct phases representation, which draws heavily on spatial ability (and/or visuospatial working memory), and solution, which does not. It is in the solution phase that core mathematical competencies are tested, the competencies that are typically the main focus of mathematical teaching in traditional engineering curricula. However, problem representation is an entirely different skill and should be considered as such so that different learning, teaching and assessment methods are considered to support its development. Architects of traditional curricula may need to reflect on this observation and consider paying greater attention in mathematics learning to the process of generating a representation of a problem before applying core competencies in the solution phase.

\section{B. Electrical Engineering-DIRECT Test}

A sizeable and significant correlation was found between spatial ability and the DIRECT test which was large in some cases, e.g. $\mathrm{r}(26)=.492, \mathrm{p}<.01$ for $3^{\text {rd }}$ year electrical engineering students at DIT. While the magnitude and significance of this correlation is not consistent across samples there is much more consistency when the test is divided into its four conceptual subsets - physical aspects of DC circuits (Group A), energy (Group B), current (Group C) and voltage (Group D). The correlation between spatial ability and Group A questions varies within a narrow range (mean $r=.45$ ) and is consistently significant at the $\mathrm{p}<.01$ level while for the other three groups the correlation is quite variable and insignificant in most cases. The average value of the correlations between the spatial test and Group A on DIRECT is .45 and all are significant at $\mathrm{p}<.01$. Between 13 and $28 \%$ of the variation in scores on Group A of DIRECT is shared with a test of spatial ability and the highest correlations are observed when the MCT is used to measure spatial ability.

All Group A DIRECT questions share a similar format which consists of a short question, an image of a circuit with multiple answer choices provided for the participant to select. According to [14], the circuits concepts assessed by Group A are arguably the fundamental aspects of circuits. Five of the Group A questions require transformation between pictorial sketch and formal circuit diagram (questions 9, 13, 18, 22 and 27). Four require some rearrangement of a formal circuit diagram (questions 4, 5, 10 and 19) and two require reasoning about circuit properties when a switch is closed (questions 14 and 23).

The format of Group A questions is different to mathematical story problems in that they do not contain a story, they do contain an image, both mental transformation and reasoning are required and answer choices are provided. While the multiple choice question format can prompt representations of the problem and facilitate guess work, those who do attempt to answer the questions are faced with decision making that can be categorised as problem representation.

\section{Electrical Engineering-General Circuits Problems}

The participants scored very high on the knowledge control questions and the Direct test electric circuit questions indicating that they had the sufficient conceptual knowledge to correctly solve the remaining problems. As shown in Figure 3, the scores on the electric circuit textbook problems were more varied. On average participants performed well on problems 2 and 5, did not perform well on problems 1 and 4 and were mixed on problem 3. The overall average score on this set of problems was 31.8 out of a 50 possible points.

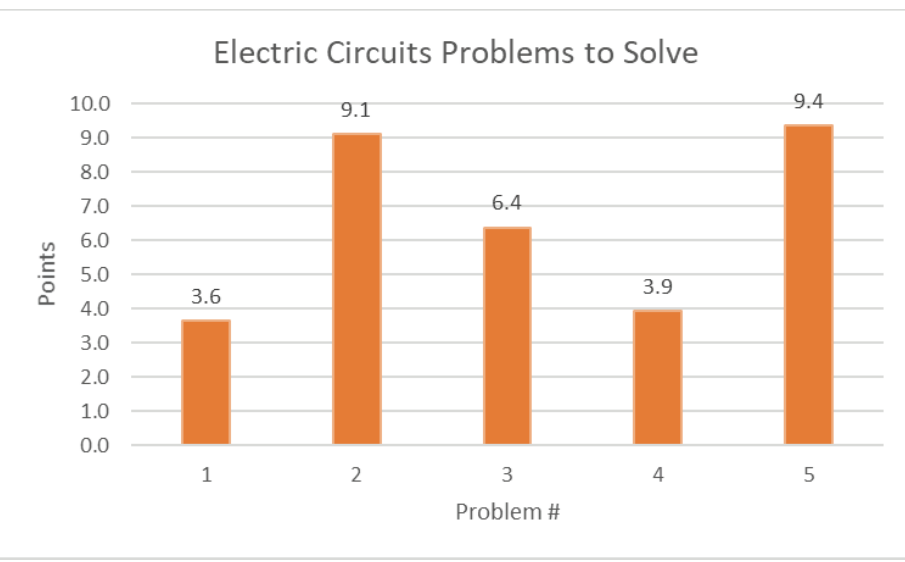

Fig. 5. Average scores on electric circuit textbook problems.

The purpose of this pilot study was to see if there were any correlations present between scores on the MCT and scores on the electric circuit textbook problems. Unfortunately, there were no statistically significant associations found between the scores on the MCT and scores on either the multiple-choice electric circuit questions or the electric circuit textbook 
problems. The relatively small sample size $(\mathrm{N}=17)$, may account for this and we will be collecting more data to see if the results change.

\section{Chemical Engineering Problems}

Problem sets were administered during a class period in Thermodynamics, a third-year course in the Chemical Engieering program, but the topics tested in the problems are typically covered in a second-year course in chemical engineering. Since the students were all given the same amount of time, those who were better at problem-solving would likely solve a larger number of problems compared to weaker students. Figure 4 shows the correlation between the number of problems correctly solved and scores on the MCT.

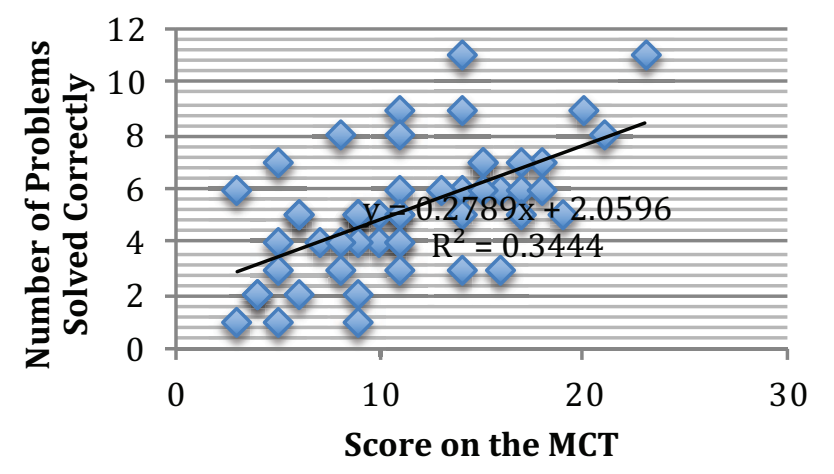

Fig. 6. Scatter Plot with Results from Chemical Engineering Problems

A strong positive correlation $(\mathrm{R}=0.59, \mathrm{p}<0.00001)$ between spatial skills test scores and the number of problems successfully solved by the students was found. Problems where spatial skills appear to play a role were identified and will be further described in the presentation.

The problems identified in this pilot study were further analyzed to determine which, if an, of the problems appeared to rely on spatial skills in their solution and which ones did not. For this analysis we computed the average MCT score of the students who solved the problem correctly and compared it to the average MCT score of those who did not solve it correctly.

The following problem is an example where spatial skills appeared not to play a role in its solution:

- A paint mixture containing $25.0 \%$ of a pigment and the balance water sells for $\$ 18.00 / \mathrm{kg}$, and a mixture containing $12.0 \%$ pigment sells for $\$ 10.00 / \mathrm{kg}$. If a paint retailer produces a blend containing $17 \%$ pigment, what should the sales price be in order to yield a $10 \%$ profit?

For this problem the average MCT for those who answered it correctly was 13.07 and for those who answered it incorrectly, the average was 11.77 (out of a possible 25 points). The difference is spatial skills as measured by the MCT was not statistically significant.

In contrast, the following problem is one where spatial skills appeared to play a role in problem solution:
- Two methanol-water mixtures are contained in separate flasks. The first mixture contains $40.0 \mathrm{wt} \%$ methanol, and the second contains $70.0 \mathrm{wt} \%$ methanol. If $200 \mathrm{~g}$ of the first mixture is combined with $150 \mathrm{~g}$ of the second, calculate the mass and composition of the product.

For this problem, the average MCT score for those who answered it incorrectly was 4.80 compared to 11.88 for those who answered it correctly. This difference was significant at the $\mathrm{p}=0.0014$ level.

The data obtained in this portion of the study is being further analyzed to determine characteristics of problems where spatial skills appear to paly a role and compare those to the types of problems where spatial skills do not appear to play a role. The two problems given here appear to be virtually the same in terms of the skills and conceptual understanding needed to solve them. So why does one appear to have a spatial component while the other does not? In future work qualitative analysis of student solutions will be conducted to attempt to answer this question.

\section{CONCLUSIONS}

Numerous studies have shown the link between welldeveloped spatial skills and engineering success. The current study examined the link between spatial skills and one specific aspect of the engineering curriculum - problem-solving. This paper includes the results from four separate studies examining the link between spatial skills and problem solving. In all but one of these studies, spatial skills were found to be important for solving problems in mathematics, electrical engineering, and in chemical engineering. One study found no correlation between spatial skills and successful circuits problem-solving; however, it should be noted that the sample size for this portion of the study was small and might not be respresentative of the general student population found in electrical engineering. Future work will examine specific aspects of student problemsolving (for example inclusion of a descriptive figure) to determine the mechanisms by which spatial skills play a role.

\section{ACKNOWLEDGMENT}

This work has been supported by funding from the National Science Foundation in the U.S. through grants number DRL1535307 and DRL-1818758.

\section{REFERENCES}

[1] C. Condon and D. Schroeder, "Statistical Bulletin 2004-6: Occupational Plots for the Foundation's Standard Test Battery," Johnson O'Connor Research Foundation, USA, 2004

[2] H. J. Kell, D. Lubinski, C. P. Benbow, and J. H. Steiger, J.H. "Creativity and technical innovation: Spatial ability's unique role. Psychological Science, vol. 24, no. 9, pp. 1831-1836, 2013.

[3] J. F. Sargent, "The U.S. Science and Engineering Workforce: Recent, Current, and Projected Employment, Wages, and Unemployment." Congressional Research Service, 2014.

[4] M. Besterfield-Sacre, M. F. Cox, M. Borrego, K. Beddoes, and J . Zhu, "Changing Engineering Education: Views of U.S. Faculty, Chairs, and Deans" Journal of Engineering Education, vol. 103, no. 2, p p. 193-219, 2014. 
[5] "The engineer of 2020: Visions of engineering in the new century," National Academy of Engineering, Washington, DC, 2004.

[6] J. J. Clement, "Algebra Word Problem Solutions: Thought Processes Underlying a Common Misconception," Journal for Research in Mathematics Education, vol. 13, no. 1, pp. 16-30, 1982.

[7] M. Hegarty, R. E. Mayer, and C. E. Green, "Comprehension of arithmetic word problems: Evidence from students' eye fixations." Journal of Educational Psychology, vol. 84, no. 1, pp. 76-84, 1992. https://doi.org/10.1037/0022-0663.84.1.76

[8] D. Coquin-Viennot, and S. Moreau, "Highlighting the role of the episodic situation model in the solving of arithmetical problems," European Journal of Psychology of Education, vol 18, no. 3, pp. 267279, 2003.

[9] P. Shah, and A. Miyake, The Cambridge Handbook of Visuospatial Thinking, New York: Cambridge University Press, 2005.

[10] National Council of Teachers of Mathematics, (http://standards.nctm.org/index.htm), 2017.

[11] R. Arnheim, “A plea for visual thinking," Critical Inquiry, vol.6, no. 3, pp. 489-497, 1980.

[12] D. L. Shea, D. Lubinski, and C. P. Benbow, "Importance of assessing spatial ability in intellectually talented young adolescents: A 20-year longitudinal study." Journal of Educational Psychology, vol. 93, no. 3, pp. 604-614, 2001.

[13] I. M. Smith, Spatial ability, its educational and social significance. London: University of London Press, 1964.

[14] J. Wai, D. Lubinski, and C. P. Benbow, "Spatial ability for STEM domains: Aligning over 50 years of cumulative psychological knowledge solidifies its importance," Journal of Educational Psychology, vol. 101, no. 4, pp. 817-835, 2009.

[15] S. Jones, and G. Burnett, "Spatial ability and learning to program" Human Technology, vol. 4, no. 1, pp. 47-61, 2008.

[16] D. H. Uttal, N. G. Meadow, E. Tipton, L. L. Hand, A. R. Alden, C. Warren, and N. S. Newcombe, "The Malleability of Spatial Skills: A Meta-Analysis of Training Studies," Psychological Bulletin, vol. 139, no. 2, p p . 352-402, 2013.

[17] L. A. Tartre, "Spatial skills, gender, and mathematics," In E.H. Fennema \& G.C. Leder (Eds.), Mathematics and Gender, New York, NY: Teachers College Press, pp. 27-59, 1990.

[18] M. C. Linn, and A. C. Petersen, "Emergence and characterization of sex differences in spatial ability: A meta-analysis," Child Development, vol. 56, pp. 1479 - 1498, 1985.

[19] D. Voyer, S. Voyer, and M. Bryden, "Magnitude of sex differences in spatial abilities: A meta-analysis and consideration of critical variables," Psychological Bulletin, vol. 117, no. 2, pp. 25-270, 1995.
[20] D. B. Hier, snd W. F. Crowley Jr., "Spatial ability in androgen-deficient men," New England Journal of Medicine, vol.36, pp. 1202-1205, 1982.

[21] I. Silverman, J. Choi, A. MacKewn, M. Fisher, J. Moro, and E. Olshansky, "Evolved mechanisms underlying wayfinding: Further studies on the hunter-gatherer theory of spatial sex differences," Evolution and Human Behavior, vol. 21, pp. 201-213, 2000.

[22] E. Fennema, and J. Sherman, "Sex-related differences in mathematics achievement, spatial visualization and affective factors," American Educational Research Journal, vol.14, no. 1, pp. 51-71, 1977.

[23] S. A. Sorby, "Developing 3-D Spatial Skills for Engineering Students," Australasian Journal of Engineering Education, vol. 13, no. 1, pp. 1-11, 2007.

[24] S. A. Sorby, "Educational Research in Developing 3-D Spatial Skills for Engineering Students," International Journal of Science Education, vol. 31, no. 3, pp. 459-480, 2009.

[25] R. B. Guay, "Purdue Spatial Visualization Test: Rotations," West Lafayette, IN, Purdue Research Foundation, 1977.

[26] Special Aptitude Test in Spatial Relations. College Entrance Examination Board, USA, 1939.

[27] J. B. Carroll, "A three-stratum theory of intelligence: Spearman's contribution," In I. Dennis \& P. Tapsfield (Eds.), Human abilities: Their nature and measurement from https://books.google.com/books?hl=en\&lr=\&id=JQXPIF6EgYC\& oi $=$ fnd $\& p g=$ PA $1 \& d q=$ ThreeStratum + Theory + of ++ intelligence $\&$ ots $=$ pNLaysHXX\&sig $=$ fm0uwps 6 DsjFEyTcAJsDfFPNoPQ, pp. 1-17, 1996

[28] P. V. Engelhardt, and R. J. Beichner, "Students' understanding of direct current resistive electrical circuits," Am J. Phys. vol. 72, no. 1, pp. 98115, 2004.

[29] L. R. Novick, and M. Bassok, Problem Solving. The Cambridge Handbook of Thinking and Reasoning, 2004.

[30] M. Kozhevnikov, M. A. Motes, and M. Hegarty, "Spatial Visualization in Physics Problem Solving. Cognitive Science, vol. 31, no. 4, pp. 549579. https://doi.org/10.1080/15326900701399897, 2007.

[31] G. A. Miller, "The magical number seven, plus or minus two: Some limits on our capacity for processing information," The Psychological Review, vol. 63, pp. 81-97, 1956.

[32] A. D. Baddeley, and R. H. Logie, "Working memory: The multiplecomponent model" In A. Miyake \& P. Shah (Eds.), Models of working memory: Mechanisms of active maintenance and executive control, New York, NY, US: Cambridge University Press. https://doi.org/10.1017/CBO9781139174909.005, pp. 28-61, 1999.

[33] M. Kyttälä, and J. E. Lehto, "Some factors underlying mathematical performance: The role of visuospatial working memory and non-verbal intelligence" European Journal of Psychology of Education, vol. 23, no. 1, pp. 77-94, 2008. 